\title{
La defensa de la propiedad intelectual en el Fichte jacobino de 1793
}

\author{
Héctor Oscar Arrese Igor \\ Profesor de Ética, Teoria Política e Filosofía dos séculos XIX e XX na Universidad \\ Pedagógica de la Provincia de Buenos Aires, Argentina
}

Ahstract: Johann G. Fichte publicó en 1793 una defensa de los derechos de propiedad intelectual. Su argumentación está estructurada en torno a los conceptos de la "materia" del libro (el material del que está hecho, su diseño, etc.) y de su "forma" (las ideas que están expresadas en él). Fichte sostiene que el autor es propietario de la "forma" del libro, por lo que no es justa la reimpresión del libro sin su permiso. En este trabajo intento mostrar que las categorías de "forma" y de "materia" pueden ser comprendidas cabalmente a la luz de la distinción que establece Fichte entre derechos alienables e inalienables.

Palabras Clave: Derecho, Copyright, Autor, Plagio, Fichte.
Johann G. Fichte published in 1793 a defense of the copyrights. His argumentation is structured upon the concepts of the "matter" of the book (the material it's made of, its design, etc.) and its "form" (the ideas which are expressed in it). Fichte argues that the author is the owner of the "form" of the book and that, because of this, the reprinting of the book without his permission is not fair. In this paper I will try to show that the categories of "form" and "matter" can be fully understood in the light of the distinction established by Fichte between alienable and not alienable rights.

Keywords: Right, Copyright, Author, Plagiarism, Fichte.

\footnotetext{
"La defensa de la propiedad intelectual en el Fichte jacobino de 1793." Héctor Oscar Arrese Igor
}

\section{Pensamientos erráticos de una noche de insomnio}

En la noche del 24 al 25 de julio de 1788 Fichte no podía dormir. Tenía 26 años y estaba de vuelta en Rammenau, su ciudad natal, en 
camino desde un trabajo de tutor que había tenido en Leipzig hacia otro en Zürich. Como manera de pasar su insomnio, compuso el texto Zufällige Gedanken in einer schlaflosen Nacht. En este texto Fichte satiriza la corrupción moral de su época, en particular la codicia comercial, las contradicciones en las leyes, el "sultanismo" de quienes gobiernan, las supersticiones religiosas, la arrogancia clerical, etc. ${ }^{1}$

Como señala Anthony La Vopa, en los Zufällige Gedanken se nota un eco rousseauniano de la crítica a la alienación de la sociedad, a pesar de que el Ginebrino no es citado en ningún momento en el texto. Allí Fichte divide a la sociedad en explotadores y en víctimas y se coloca a sí mismo entre los más desfavorecidos, abatido por la impresión de que no puede labrarse un lugar en el mundo social. ${ }^{2}$ Es decir que la búsqueda de Fichte de insertarse en el ámbito académico era de alguna manera también una lucha por el reconocimiento, sobre todo atendiendo a que venía de un hogar socio-económico humilde.

Los académicos se sentían una casta especial, y el caso de Fichte no era la excepción. Como puede deducirse de los Zufällige Gedanken einer scblaflosen Nacbt, la meritocracia del mundo académico era vista como superior, por un lado, al "orgullo monetario" del comerciante y del burgués y, por el otro, al "orgullo del pedigree" de la nobleza y la aristocracia. Por lo tanto, Fichte creía que los académicos debían estar alejados de la tentación del dinero, omnipresente en aquella sociedad comercial, como él mismo observó al regresar a Leipzig en el verano de $1790 .^{3}$

Por otro lado, en la Alemania de fines del siglo XVIII eran pocos los académicos, lo que les ofrecía posibilidades concretas de ascenso y reconocimiento social. Hacia 1780, cuando Fichte comenzó sus estudios, en toda la Europa germano parlante se contaban alrededor de 3.700 estudiantes universitarios, y alrededor del $25 \%$ de los adultos eran graduados. La posibilidad de trabajar como tutores les daba a jóvenes que provenían de estratos sociales bajos, como Fichte, la

1. LA VOPA, A. J. Fichte. The Self and the Calling of Philosopby, 1762-1799. Cambridge: Cambridge University Press, 2009, p. 23. Ver Fichte, J. G. Zufällige Gedanken in einer scblaflosen Nacbt. In: Lauth, R., Jacob, H. J. G. Fichte - Gesamtausgabe der Bayerischen Akademie der Wissenschaften. Stuttgart - Bad Cannstatt: Friedrich Frommann Verlag, 1962, Band 1.

2. LA VOPA, A. J. Fichte, pp. 28-29.

3. Idem, p. 42. 
oportunidad de refinar sus modales y entrar en contacto con el mundo y las clases privilegiadas. ${ }^{4}$

La conciencia que Fichte tenía de su status social como académico y de la necesidad de integrarse en los estratos superiores puede verse claramente en una carta que le envió a su hermano Samuel Gotthelf en 1794, quien quería ingresar a la Universidad de Jena, donde Fichte ya se desempeñaba como Profesor. En esta carta Fichte le explica que para ser un académico debe pulir sus modales campesinos, así como depurar su acento de Lausania a fin de hablar un alemán más refinado. Fichte mismo le declara a su hermano que él todavía conserva los modos campesinos y que no logró nunca hablar bien en francés. $^{5}$

Sin embargo, a partir de 1790 Fichte comienza a replantearse su rol como intelectual a partir de los sucesos revolucionarios en desarrollo, que desde Francia interpelaban a toda Europa. En tanto que pensador, Fichte se veía a sí mismo como parte de un espacio público en creciente expansión, que abría posibilidades inéditas para el progreso moral y social. Era allí donde se debía dar la batalla para realizar los ideales humanitarios nacidos al calor de la lucha social.

La idea de un espacio público libre del poder estatal, donde los sujetos pueden formar su opinión política por medio del intercambio libre de argumentos, surgió en el siglo XVIII para poner en cuestión a la nobleza y la monarquía, a fin de descentralizar su poder. ${ }^{6}$ En un

4. Idem, p. 43. Sobre esta problemática en general, puede verse LA VOPA, J. Grace, Talent and Merit. Poor students, clerical careers and professional ideology in eighteenth century Germany. Cambridge-New York-New Rochelle-Melbourne-Sidney: Cambridge University Press, 2002.

5. LA VOPA, A. J. Fichte, pp. 43-44.

6. HONNETH, A. Das Recht der Freibeit. Grundriss einer demokratischen Sittlichkeit. Frankfurt am Main: Suhrkamp, 2011, pp. 474-475 y 480. El gobierno prusiano comprendió las repercusiones políticas de estos procesos intelectuales, imponiendo sendas censuras, como puede verse el escrito promulgado por Federico II en 1784. HABERMAS, J. Strukturwandel der Öffentlicbkeit. Untersucbungen zu einer Kategorie der bürgerlichen Gesellscbaft. Frankfurt am Main: Suhrkamp, 1990, p. 84. Acerca de las relaciones que pueden establecerse entre el concepto habermasiano de opinión pública y el surgimiento del copyright en Inglaterra con el Estatuto de Anne en 1710, puede verse: ROSE, M. The Public Sphere and the Emergence of Copyright: Aeropagitica, Stationer's Company, and the Statute of Anne. In: DEAZLEY, R., 
primer momento surgieron los salones, donde los varones de cierta fortuna se encontraban a debatir temas de interés, a partir de la lectura de publicaciones y periódicos que circulaban profusamente por el ambiente ilustrado.

Ahora bien, de esta esfera pública primitiva del siglo XVIII estaban excluidos varios miembros de la sociedad, tales como las mujeres, los jornaleros, los trabajadores asalariados, etc. Por otro lado, estos grupos sociales también estaban excluidos de los derechos civiles individuales, que empezaban a imponerse con las primeras revoluciones burguesas. Sin embargo, entre ellos también comenzaron a formarse espacios de publicidad política, en medio de debates crecientes. El espacio donde esta publicidad era posible estaba constituido por las cajas de apoyo y las organizaciones de auto-ayuda, que permitían a los artesanos y trabajadores asalariados enfrentar las contingencias del mercado de trabajo. Por otro lado, es en estos espacios donde se organizaron las primeras luchas sociales y huelgas. ${ }^{7}$.

En este contexto Fichte se plantea el problema de la propiedad intelectual, como modo de proteger y garantizar la libre circulación de las ideas, lo que era vital para la construcción de una esfera pública deliberativa. De este modo, Fichte ya no busca un puesto seguro como académico que le permita integrarse en el status quo, sino que intenta contribuir a la formación de una sociedad más libre, donde los ciudadanos puedan desarrollar su autonomía moral sin obstáculos. En lo que sigue consideraré el problema de la propiedad intelectual, tal como es tratado en "Beweis der Unrechtmäßigkeit des Büchernachdrucks", publicado en 1793, en el contexto del contractualismo de Fichte, en especial de su distinción entre derechos alienables e inalienables.

\section{El derecho a la propiedad intelectual}

El texto de Fichte constituye una respuesta a otro texto de Reimarus, publicado en 1791 bajo el título „La edición de libros en consideración del escritor, del editor y del público, nuevamente examinada" "Der Bücherverlag in Betrachtung der Schriftsteller, der Verleger, und des Publikum, nochmals erwogen"). En este texto,

KRETSCHMER, M., BENTLY, L. (eds.), Privilege and Property. Essays on the History of Copyright. Cambridge: Open Books Publishers, 2010, pp. 67-88.

7. HONNETH, A. Das Recht der Freibeit, pp. 476-477. 
Reimarus habría sostenido que no puede demostrarse que el autor tenga algún derecho permanente sobre su texto, de modo tal de estar en condiciones de prohibir su reimpresión. Por otro lado, Reimarus, sostiene en dicho texto que la reimpresión de los textos puede ser de mucha utilidad, por lo que recomienda esta práctica. ${ }^{8}$ Sin embargo, deja abierto el problema de la determinación definitiva de la ausencia de derechos de autor, dado que no cree disponer de fundamentos definitivos para zanjar la cuestión.

Fichte acompaña su alegato con una parábola, que puede ayudarnos a ubicar mejor el problema del que aquí se trata. Fichte sitúa su parábola en los tiempos en que reinaba el Califa Harún Al Raschid, conocido por su sabiduría a través de Las mil y una noches. En aquel entonces un hombre había logrado elaborar un extracto a partir de hierbas y sales, que supuestamente podía ayudar contra todo tipo de enfermedades e incluso a evitar la muerte misma. Si bien el extracto no tenía todas las propiedades medicinales que su fabricante le atribuía, se trataba de una medicina bastante buena y efectiva. Para disponer del tiempo suficiente para sus experimentos químicos, delegó la comercialización del extracto en manos de un vendedor, quien recorrió todo el país y logró abundantes ganancias. ${ }^{9}$

Los demás comerciantes de medicamentos, movidos por la envidia, intentaron difamar el comerciante y a su extracto. Sin embargo, uno de ellos decidió robar el extracto a los ayudantes del comerciante, cuando lo traían del local del químico. Este ladrón lo vendió en cada ciudad, aldea y caserío, a un precio muy accesible, con un gran éxito. El antiguo comerciante del extracto informó del robo a todas las ciudades y pueblos por los que podría pasar el ladrón, y se lo comunicó también a los otros comerciantes. ${ }^{10}$ Durante mucho tiempo, el comerciante intentó atrapar al ladrón, pero éste se le escabullía con mucha astucia. Finalmente, el ladrón se volvió confiado, a causa de su suerte, y se distrajo, cayendo en manos del antiguo comerciante.

8. FICHTE, J. G. Beweis der Unrechtmäßigkeit des Büchernachdrucks. Ein Räsonnement und eine Parabel. In: FICHTE, I. H. (ed.), Jobann Gottlieb Fichte's Sämtliche Werke. Berlín: Verlag von Veit \& Comp, 1846, Band VIII, pp. 223-244. Aquí: p. 224.

9. FICHTE, J. G. Beweis der Unrechtmäßigkeit des Büchernachdrucks, pp. 239-240

10. Idem, p. 240. 
Luego fue llevado ante el Califa, para comparecer en tanto que acusado del delito de robo.

Ya frente al Califa, y movido por la audacia y la elocuencia que había adquirido durante la venta del extracto, el ladrón ensayó una defensa que rezaba como sigue. En primer lugar, apeló a la utilidad, como valor supremo, la que consistía en la producción de las ventajas (Vortheile) más significativas para la mayor cantidad de personas posible. Por otro lado, el ladrón sostuvo que la justicia no es algo realizable en esta vida, sino un mero ideal ficticio al que apelaban algunos tontos. La apelación a la justicia podría llegar incluso a provocar la muerte por hambre. Pero el Califa había establecido la nueva regla ilustrada de la utilidad, que debía ser preferida a las ideas anticuadas de la corrección y la justicia. ${ }^{11}$

Utilizando el criterio de la utilidad, el ladrón comenzó a señalar las ventajas que su práctica trajo al país, comenzando por el precio más accesible, que permitió curarse a mucha gente que antes no podía afrontar los costos del extracto. Además la elocuencia con la que vendía el extracto motivaba a la gente a tomarlo y a curarse. El extracto había salvado a mucha gente de las agonías de la muerte y a muchos padres les había permitido recuperarse y criar sus hijos, convirtiéndolos en buenos ciudadanos. Asimismo, estos mismos niños criarían luego a sus hijos y también los harían buenos ciudadanos del país. También habría permitido volver a la salud a los científicos, a los artistas y a los profesionales, quienes podrían de este modo seguir enriqueciendo a la cultura de la comunidad. ${ }^{12}$

A estas consideraciones de utilidad, el ladrón agregó que sufría una persecución constante por parte del del antiguo vendedor, lo que lo obligaba a contratar a los trabajadores menos cuidadosos, con las consecuencias desastrosas que ésto implicaba. ${ }^{13}$ En un momento posterior el ladrón se defendió frente al Califa de la acusación de llevar al inventor del extracto a abandonar su trabajo de investigación y de producción. Contra ésto el ladrón argumentó que el inventor en realidad no realizaba su trabajo en razón de la obtención de ganancias financieras, sino más bien por puro amor a la tarea misma o, cuanto mucho, por amor al honor que proviene de ser un benefactor de la

\footnotetext{
11. Idem, pp. 240-241.

12. Idem, p. 241.

13. Idem, p. 242.
} 
humanidad. La venta del extracto había llevado el nombre del inventor hasta los confines del país, provocando admiración y reconocimiento en la gente, con lo que le hizo un gran servicio a su reconocimiento, lo que es un premio aún mucho mayor que el dinero. ${ }^{14}$ Mas aún, el robo del extracto obligaría al inventor a producir más cantidad de extracto para poder cubrir sus necesidades básicas. De este modo, aumentaría la cantidad total de extracto producido y con ello habría mucho más disponible para quien lo necesitara. ${ }^{15}$

El ladrón pidió al Califa, a cambio de todos los beneficios que brindó al país, que cese el reclamo legal en su contra, que el antiguo comerciante le pida disculpas por todas las persecuciones y las acechanzas $y$, finalmente, le permita robar la cantidad de extracto que quiera, y cuando quiera. Acto seguido, Fichte pregunta a su interlocutor Reimarus, así como a toda persona dotada de algún sentido de justicia, qué decisión tomarían frente a un alegato de ese tipo. A modo de respuesta, dice Fichte que el Calida hizo lo mismo que hubieran hecho ellos: colgar de la horca a una persona tan beneficiosa y positiva. ${ }^{16}$

Esta parábola nos anticipa el razonamiento de Fichte, que culminará con el rechazo tajante de la reimpresión de libros sin autorización del autor. Pero vayamos por parte y veamos el argumento con algún detalle. Como se deduce de la parábola, Fichte no considera relevante el problema de la utilidad de los derechos de autor, porque su legalidad es lo determinante a la hora de permitir o no la reimpresión de los libros sin permiso. ${ }^{17}$

El punto de partida del argumento viene dado por el análisis de una serie de máximas que sostienen quienes en general han sido bien educados en la materia en cuestión y manifiestan una intención recta. De allí Fichte concluye que estas máximas pueden reducirse con relativa facilidad a un sólo principio. Fichte comienza entonces definiendo dicho principio, para luego mostrar que se trata efectivamente del principio que está a la base de todos nuestros juicios sobre el problema de los derechos de autor.

\footnotetext{
14. Idem, ibidem.

15. Idem, ibidem.

16. Idem, p. 244.

17. Idem, p. 224.
} 
El principio del que parte Fichte consiste en que la propiedad de algo se funda en la imposibilidad de otro de apropiarse físicamente de ella. ${ }^{18} \mathrm{El}$ paso siguiente en el argumento consistirá entonces en mostrar que un libro es una cosa de este tipo.

Para arribar a esta conclusión, Fichte distingue en un primer momento entre dos dimensiones de un libro. Por un lado, está la dimensión corpórea, es decir el papel impreso y, por el otro, la dimensión espiritual, o sea las ideas que se expresan en el libro. ${ }^{19}$ Ahora bien, propiedad de la dimensión material del libro es transmitida al comprador por medio de la transacción comercial. Entonces el comprador puede leer el libro, prestarlo, venderlo de nuevo al precio que quiera, quemarlo, usarlo para tapizar una pared, etc., pero ésto no significa que sea propietario también de la dimensión espiritual del libro. Esta dimensión es más compleja que la material, porque puede dividirse a su vez en en la materia o contenido del libro, es decir las ideas que en él se expresan y, por otro lado, en la forma, esto es la elaboración y expresión lingüística de las mismas. ${ }^{20}$

La materia no puede convertirse en propiedad de quien compra o adquiere el libro de alguna manera. Es decir que el libro pase de una mano a otra no implica lo hagan los pensamientos que están allí contenidos, porque éstos no pueden adquirirse con la mera apropiación física del libro, para llevarlo a nuestra casa y ubicarlo en nuestra biblioteca. ${ }^{21}$ Por el contrario, para apropiarnos de las ideas desarrolladas en un libro es necesario en primer lugar examinar y estudiar el texto

18. Con palabras de Fichte: "nosotros necesariamente conservamos la propiedad de aquella cosa cuya apropiación es físicamente imposible por parte de otro" ["Wir bebalten notbwendig das Eigenthum eines Dinges, dessen Zueignung durch einen Andern physisch unmöglich ist"] (Idem, p. 225).

19. Idem.

20. Friedemann Kawohl y Martin Kretschmer han intentado mostrar que la aproximación restrictiva al problema de la violación del copyright, aplicado, por ejemplo, a conciertos o recitales, proviene de la distinción que Fichte realiza entre contenido y forma. Ver KAWOHL, F, KRETSCHMER, M. Johann Gottlieb Fichte, and The Trap of Inhalt (Content) and Form: An Information Perspective on Music Copyright. In: Information, Communication \& Society, Volume 12, Issue 2, 2009, pp. 41-64.

21. FICHTE, J. G. Beweis der Unrechtmäßigkeit des Büchernachdrucks, pp. $225-226$. 
a fondo, para luego integrar sus ideas en la red de conocimientos propios de cada uno. Con la compra del libro en realidad accedemos a la posibilidad de hacer propios los pensamientos del autor, para lo que necesitamos aplicar nuestro esfuerzo intelectual. ${ }^{22}$

Fichte parte de que cada uno tiene su propia manera particular de adquirir conceptos y de vincularlos entre sí. De este modo, aún el procesamiento de los pensamientos ajenos exige que los relacionemos entre sí de acuerdo con nuestro modo de pensar particular e individual. Por lo tanto, es imposible que dos sujetos alineen y vinculen sus pensamientos de la misma manera, entre sí y con las mismas imágenes. ${ }^{23}$ Cada escritor entonces elabora y procesa sus ideas a su manera y nadie más puede hacerlo como él, por lo que la publicación de sus pensamientos no puede convertirlos sin más en los pensamientos de los demás. Esto implica a su vez que la forma del texto permanece siendo su propiedad exclusiva, dado que nadie puede apropiársela sin modicarla en el mismo momento. ${ }^{24}$

De estos pasos Fichte deduce que nadie tiene derecho a privar al autor de la propiedad de la forma del texto y, por lo tanto, debe ser reconocido como tal, por lo que nadie tiene tampoco derecho a impedir que él ejerza de modo exclusivo la propiedad del texto. ${ }^{25}$ Pero tampoco es legítimo el plagio de un texto, es decir la copia textual del mismo sin citar ni reconocer a quien lo ha escrito. Ante todo, este comportamiento es objeto de una sanción moral general, aún en el caso de que se haya copiado un texto que no puede conseguirse fácilmente. ${ }^{26}$ Sin embargo, no nos parece moralmente reprobable la aplicación de las ideas de otro autor, porque para realizar esta operación

22. Idem, p. 226.

23. Mayeda sostiene que Fichte ofrece aquí una prueba fenomenológica de su punto de partida, al apelar a nuestra experiencia cotidiana, que nos mostraría que somos incapaces de valernos de las imágenes de otras personas para expresar nuestras propias ideas. Ver MAYEDA, G. Commentary on Fichte's 'The Illegality of the Unauthorised Reprinting of Books': An Essay on Intellectual Property During the Age of the Enlightenment. In: University of Ottawa Law \& Technology Journal, 5: 1\&2, 2008, pp. 141-197. Aquí: p. 150.

24. FICHTE, J. G. Beweis der Unrechtmäßigkeit des Büchernachdrucks, pp. 227-228.

25. Idem, p. 228

26. Idem, p. 229. 
debemos apropiarnos en primer lugar de sus ideas y luego darles nuestra propia forma, es decir vincularlas entre sí y expresarlas según nuestra forma particular e individual de hacerlo. ${ }^{27}$

Tampoco es reprobable que alguien retome las ideas de otro, citándolas adecuadamente, para luego construir sobre ellas nuevas ideas, permitiendo de este modo el avance y el progreso del conocimiento humano. ${ }^{28}$ Por otro lado, ningún docente permite que se reimpriman sus lecciones sin su autorización, aunque nadie tiene problema con que sus alumnos reproduzcan sus enseñanzas por escrito u oralmente, dado que esto último implica que han reelaborado sus ideas de acuerdo con la forma particular que tiene cada uno de pensar y de expresarse. ${ }^{29}$

En un momento posterior Fichte intenta aplicar los principios a los que ha arribado a las relaciones entre el autor y el editor. La primera pregunta que surge es qué tipo de derecho de propiedad el autor le traspasa al editor, en la medida en que pone en sus manos su manuscrito. Como el autor no puede entregar la forma del manuscrito en propiedad a nadie, lo que traspasa en el contrato al editor es en realidad el usufructo (Niessbraucb) del mismo, bajo ciertas condiciones. Lo que el editor posee en realidad es el derecho a vender a los compradores el derecho a acceder a las ideas que el texto contiene. Por lo tanto, el editor gestiona la venta de esta propiedad en representación del autor del texto. ${ }^{30}$ Por eso el autor tiene derecho a impedir que el editor imprima más ejemplares de su manuscrito, respecto de la cantidad convenida por los dos en el contrato de la edición.

Quien reimprime el texto sin permiso del autor entonces se arroga su representación, sin que medie un contrato entre ellos dos. ${ }^{31}$ Por lo tanto, tiene el usufructo del texto e y hace posible que los demás accedan legítimamente a las ideas del autor. En este punto, Fichte considera relevante separar las consideraciones de derecho respecto de las consideraciones de utilidad. Es decir que el hecho de que la reimpresión ilegal le acarree ventajas al escritor, difundiendo su obra

\footnotetext{
27. Idem, ibidem.

28. Idem, pp. 229-230.

29. Idem, p. 230.

30. Idem, p. 231.

31. Idem, p. 232.
} 
hasta en los confines más lejanos del imperio, no quita en nada al hecho de que se trata un hecho injusto y de una violación fragrante de los derechos de autor. ${ }^{32}$

Por el contrario, Fichte considera que el plagio o la reimpresión constituyen delitos que deben llevar las penas más graves, porque un texto es muy difícil de custodiar y de resguardar y, por lo tanto, puede ser reproducido ilegalmente con cierta facilidad. Por otro lado, se trata de un producto extremadamente noble, en tanto que pertenece a la cultura del espíritu (Geisteskultur), lo que amerita la aplicación de penas particularmente severas. Por eso Fichte se refiere a estos delitos como "robos librescos" (Bücherdiebereien) y a quienes los perpetran como a ladrones. ${ }^{33}$

Ahora bien, si la forma del texto, es decir su contenido, le pertenece en propiedad al autor, cuando éste último ha muerto, pasa a sus herederos quienes, una vez que han desaparecido legan esta propiedad a la sociedad en su totalidad. En el caso de que alguien desee copiar el texto a mano y vender la copia manuscrita sin autorización del autor, probablemente no tenga sentido perseguirlo, porque el pago miserable que pueda llegar a recibir el copista sería desproporcionado respecto de su esfuerzo y, por otro lado, no llegaría a producir ningún daño relevante al autor. Sin enbargo, si el autor quisiera renunciar a su derecho y conceder el permiso a determinadas personas para que reproduzcan su texto, podría hacerlo, dado que todos pueden renunciar a su derecho cuando así lo deseen, sin perjuicio de que puedan volver a ejercerlo a voluntad. Esto vale aún en el caso de que el autor les otorgue el consentimiento de modo modo tácito, callando en conocimiento de los hechos. ${ }^{34}$

Atendiendo a la analogía que algunos han establecido entre la prohibición de reimprimir libros sin el consentimiento del autor y la de imitar las obras de arte producidas mecánicamente, Fichte se centra en el análisis de estas últimas. En principio Fichte no ve razón alguna para prohibir su imitación, dado que han sido elaboradas según una regla fácil de descubrir y, por lo tanto, de imitar. En realidad estas obras no tienen "forma" en cuanto que no son expresión de una serie de ideas unidas entre sí según la personalidad individual de su inven-

\footnotetext{
32. Idem, pp. 232-233.

33. Idem, p. 233.

34. Idem, pp. 233-234.
} 
tor, como sí ocurre en los libros. Por lo tanto, el inventor no tiene ninguna propiedad intelectual inalienable que haya que proteger. ${ }^{35}$

Sin embargo, Fichte considera que, dado que el inventor ha invertido su tiempo y su dinero $y$, por lo tanto, tiene derecho a vivir de su trabajo, el Estado puede intervenir de oficio y dictar un privilegio (Privilegium), de modo tal de exigir una cierta compensación para el perjudicado. ${ }^{36} \mathrm{G}$. Mayeda sostiene que este pasaje remite a la idea posterior, presente en el Grundlage des Naturrecbts, de un derecho de toda la ciudadanía a poder vivir de su trabajo (das Lebenkönnen). ${ }^{37}$

Por otro lado, el texto de Reimarus, que Fichte discute aquí, conduce a alguna forma de privilegio, destinada a proteger la reimpresión de determinados libros. Pero Fichte desenmascara este tipo de propuestas, que presuponen un derecho natural a reimprimir todos los libros que se deseen. Los privilegios estarían destinados simplemente a la suspensión momentánea de esta ley natural, por razones determinadas de coyuntura. ${ }^{38}$

A su vez, el concepto de privilegio estaba basado en la antigua idea de autoría, según la cual el libro era un medio para transmitir ideas que el autor recibía de fuentes externas a él, es decir de la inspiración divina o de las musas. Por lo tanto, la compensación monetaria que el autor recibía por su trabajo era más un bonorarium y no una remuneración por el trabajo intelectual que estaba detrás de su obra. ${ }^{39}$ Frente a la concepción renacentista de la autoría, originada en fuentes de inspiración externas al autor, la concepción fichteana consiste en que el autor produce la obra a partir de su propia inspiración interior,

35. Idem, pp. 234-235.

36. Idem, p. 236.

37. Idem, p. 168.

38. Idem, p. 237. El texto de Fichte fue publicado en una época en que el concepto de privilegio estaba siendo reemplazado progresivamente por el de copyright. Por ejemplo, en 1774, la Cámara de los Lores (House of the Lords), en el caso Donaldson versus Becket, reconoció la propiedad del autor sobre su obra, pero permitió al Parlamento poner límites a su derecho, en relación con la duración de la vigencia del copyright. MAYEDA, G. Commentary on Fichte's 'The Illegality of the Unauthorised Reprinting of Books', p. 145.

39. Idem, pp. 146 y 153. 
por lo que debe reconocerse legalmente que él es la fuente de sus ideas. ${ }^{40}$

Hasta aquí la argumentación de Fichte. El siguiente problema tiene que ver con el marco teórico y sistemático en el que se mueve este fuerte alegato a favor de los derechos de autor. G. Mayeda sostiene que la concepción filosófica que está a la base de este texto es la idea de que la obra constituye la libre expresión de la individualidad del autor. ${ }^{41}$ Si bien es verdad que Fichte utiliza en su favor la tesis de que el proceso de pensamiento es absolutamente idiosincrático e individual, creo que también debe tomarse en cuenta la idea de contrato social que Fichte defendía en la misma época en la que redactó este alegato.

Fichte entró en el debate político gracias a dos obras en las que abogó por la Revolución Francesa: Reivindicación de la libertad de pensamiento, de 1793, (Zurückforderung der Denkfreibeit) y Contribución a la rectificación de los juicios del público sobre la Revolución Francesa, publicado en 1794 (Beitrag zur Bericbtigung der Urtheile des Publicums über die französische Revolution). ${ }^{42}$ Estos textos contienen una teoría de la justicia fundada en el derecho de los ciudadanos a formularse su propia ley moral y a obedecer a nadie más que a la misma. Este derecho es inalienable, en la teoría del joven Fichte, frente al carácter alienable que tiene el derecho a la acción externa (äussere Handlung), la que es cedida voluntariamente por el individuo en el acto del contrato social. ${ }^{43}$

En este contexto, Fichte enarboló una enérgica defensa de la libertad de expresión, aún en el caso de que la expresión de las propias

40. Idem, p. 153.

41. Idem, p. 152.

42. FICHTE, J. G. Zurückforferung der Denkfreibeit von den Fürsten Europens, die sie bisher unterdrückten. Eine Rede. In: FICHTE, I. H. (ed.), Jobann Gottlieb Ficbte's Sämtliche Werke. Berlín: Verlag von Veit \& Comp, 1846, Band VI, pp. 1-35. FICHTE, J. G. Beitrag zur Berichtigung der Urtheile des Publicums über die französische Revolution. In: Fichte, I. H. (ed.), Jobann Gottlieb Fichte's Sämtliche Werke, pp. 137-288. Acerca del trasfondofilosófico del Beitrag puede verse, PHILONENKO, A. Théorie et Praxis dans la penseé morale el politique de Kant et Fichte en 1793. Paris: Librairie Philosophique J. Vrin, 1988, pp. 113-123. Sobre los debates religiosos detrás del Beitrag, ver PHILONENKO, A. La destination du jeune Fichte. Paris: Librairie Philosophique J. Vrin, 2008, pp. 19-33.

43. FICHTE, J. G. Zurückforferung der Denkfreibeit von den Fürsten Europens, pp. 12-13. 
opiniones ofendieran a las convicciones de los demás, porque los demás siempre están condiciones de examinarlas racionalmente y de declararlas inválidas. Por otro lado, también debe dejarse libre a los ciudadanos para que tomen de las opiniones ajenas aquello que consideren válido, en el caso de que así lo deseen. La comunicación de las propias opiniones a los demás también acarrea consecuencias beneficiosas para el desarrollo de la propia personalidad, dado que nos permite someterlas a escrutinio y a debate, así como autoaclararnos al respecto. Por estas razones, Fichte sostiene que la libertad de expresión es un derecho inalienable y no puede ser cedido en el acto del contrato social. ${ }^{44}$ Este modelo de Estado sería la mediación, desde el punto de vista de Fichte, para que la sociedad avance desde una mera obediencia ciega a las leyes, por miedo a la sanción penal resultante, a una comunidad donde los ciudadanos se autolegislen y, por lo tanto, se gobiernen a sí mismos. ${ }^{45}$

El texto de Fichte contra la reimpresión de libros no puede comprenderse cabalmente si no es en el contexto de su pensamiento político revolucionario. Considero que la distinción entre la materia y la forma del texto, que es el eje sobre el que pivota el argumento, es paralela a aquella que Fichte establece entre derechos alienables e inalienables. Del mismo modo que nadie puede alienar su derecho a la libertad de expresión, nadie puede alienar su derecho a la propiedad de sus propias ideas. Por lo tanto, el autor debe permanecer dueño de sus propias ideas, para poder expresar su voz en el espacio de lo público. A su vez, tal como en el contrato social fichteano cada ciudadano puede ceder el derecho a la acción externa, es decir a las condiciones materiales de la acción, el autor puede ceder el derecho a las condiciones materiales de producción del libro (el material del que está hecho, su diseño, etc.).

La propiedad intelectual tiene entonces sentido en tanto que protección de la autonomía individual, que es la única condición del progreso moral. Fichte no volvió a tratar este problema en su Grundlage des Naturrecbts, de 1796/1797. Si lo hubiera hecho, seguramente que su

44. Idem, pp. 15-17.

45. RAMETTA, G. Politik der Vernunft und Vernunftstaat bei Fichte (1793-1808). In: DE PASCALE, C., FUCHS, E., IVALDO, M., ZÖLLER, G., (eds.), Fichte und die Aufklärung. Hildesheim-Zürich-Nueva York: Georg Olms Verlag, 2004, pp. 227-241. Aquí: p. 231. 
respuesta hubiera sido diferente, al menos en relación con algunas consecuencias de la propiedad intelectual. En su tratado del derecho natural el derecho fundamental, sobre el que está estructurado todo el sistema de la propiedad, es el derecho a la existencia. Por lo tanto, es probable que Fichte habría limitado los derechos de propiedad intelectual en aquellos casos en que se publicaran descubrimientos científicos que hicieran a la supervivencia de la población. En estos casos no es razonable pensar que Fichte los habría suprimido totalmente, pero seguramente que los habría limitado, en razón de la autoconservación de los ciudadanos en la existencia. Más aún, quizás hubiera escuchado al ladrón del elixir acerca de las consecuencias ventajosas de poner a la salud de la población por sobre las prerrogativas del inventor del remedio milagroso.

\section{Bibliografía:}

FICHTE, J. G. Zufällige Gedanken in einer schlaflosen Nacht. In: LAUTH, R., JACOB, H., J. G. Fichte - Gesamtausgabe der Bayerischen Akademie der Wissenschaften. Stuttgart Bad Cannstatt: Friedrich Frommann Verlag, Nachgelassene Schriften, 1962, Band 1, pp. 103-110. Zurückforferung der Denkfreiheit von den Fürsten Europens, die sie bisher unterdrückten. Eine Rede, 1793. In: Fichte, I. H. (ed.), Jobann Gottlieb Fichte's Sämtliche Werke. Berlín: Verlag von Veit \& Comp, 1846, Band VI, pp. 1-35.

Beweis der Unrechtmäßigkeit des Büchernachdrucks. Ein Räsonnement und eine Parabel. In: FICHTE, I. H. (ed.), Jobann Gottlieb Fichte's Sämtliche Werke. Berlín: Verlag von Veit \& Comp, 1846, Band VIII, pp. 223-244.

Beitrag zur Berichtigung der Urtheile des Publicums über die französische Revolution. In: FICHTE, I. H. (ed.), Johann Gottlieb Fichte's Sämtliche Werke. Berlín: Verlag von Veit \& Comp, 1846, Band VI, pp. 137-288.

HABERMAS, J. Strukturwandel der Öffentlichkeit. Untersucbungen zu einer Kategorie der bürgerlichen Gesellschaft. Frankfurt am Main: Suhrkamp, 1990.

HONNETH, A. Das Recht der Freibeit. Grundriss einer demokratischen Sittlicbkeit. Frankfurt am Main: Suhrkamp, 2011.

KAWOHL, F., KRETSCHMER, M. Johann Gottlieb Fichte, and The Trap of Inhalt (Content) and Form: An Information Perspective on 
Music Copyright. In: Information, Communication \& Society, Volume 12, Issue 2, 2009, pp. 41-64.

LA VOPA, A. J. Grace, Talent and Merit. Poor students, clerical careers and professional ideology in eighteenth century Germany. Cambridge-New York-New Rochelle-Melbourne-Sidney: Cambridge University Press, 2002.

LA VOPA, A. J. Fichte. The Self and the Calling of Philosophy, 1762-1799. Cambridge: Cambridge University Press, 2009.

MAYEDA, G. Commentary on Fichte's 'The Illegality of the Unauthorised Reprinting of Books': An Essay on Intellectual Property During the Age of the Enlightenment. In: University of Ottawa Law \& Technology Journal, 5: 1\&2, 2008, pp. 141-197.

PHILONENKO, A. Théorie et Praxis dans la penseé morale el politique de Kant et Fichte en 1793. Paris: Librairie Philosophique J. Vrin, 1988.

PHILONENKO, A. La destination du jeune Fichte. Paris: Librairie Philosophique J. Vrin, 2008.

RAMETTA, G. Politik der Vernunft und Vernunftstaat bei Fichte (17931808). In: DE PASCALE, C., FUCHS, E., IVALDO, M., ZÖLLER, G., (eds.), Fichte und die Aufklärung. Hildesheim-Zürich-Nueva York: Georg Olms Verlag, 2004, pp. 227-241.

ROSE, M. The Public Sphere and the Emergence of Copyright: Aeropagitica, Stationer's Company, and the Statute of Anne. In: DEAZLEY, R., KRETSCHMER, M., BENTLY, L., (eds.) Privilege and Property. Essays on the History of Copyright. Cambridge: Open Books Publishers, 2010, pp. 67-88. 